\title{
ANTHROPOLOGY AND OCCUPATIONAL HEALTH PROBLEMS OF AUTO-RICKSHAW DRIVERS
}

\author{
Thangjam Chitralekha Devi ${ }^{1}$, Khuraijam Geetamani Devi ${ }^{1}$, \\ Khangembam Taibanganba Meitei ${ }^{1}$, Brahmacharimayum \\ Surajkumar Sharma ${ }^{2}$, Huidrom Suraj Singh ${ }^{1}$ \\ ${ }^{1}$ Department of Anthropology, Manipur University, Canchipur, Imphal, \\ Manipur, India \\ ${ }^{2}$ Department of Anthropology, D.M. College of Science, Dhanamanjuri \\ University, Imphal, Manipur, India
}

\begin{abstract}
Driving an auto-rickshaw has become one of the most common and easiest ways of earning a living, particularly for educated unemployed youths of Manipur. In the present study an attempt was made to understand the health status of auto-rickshaw drivers plying in different locations of Imphal, Manipur. A cross-sectional study was conducted among the auto-rickshaw drivers of Imphal, Manipur. A total of 159 auto-rickshaw drivers (aged 20-65 years) were screened to understand their health status and potential risk factors associated with cardiovascular diseases (CVD). The data were analysed using different statistical measures including mean, t-test, the test of significance, using MS Excel and SPSS software. Odds ratio (OR) was also calculated to measure the association (if any) using the $2 \times 2$ contingency table at $95 \%$ confidentiality interval. The majority of the drivers were educated and married. Vision impairment, body and neck pain are the commonest morbidity conditions generally faced by the drivers. Individuals who have been driving for more than ten years are at a significantly greater risk for diabetes, obesity, hypertension, and anaemia compared to those who have been driving up to five years. Persons who have worked for a long time in the same occupation as an auto-rickshaw driver are more prone to have mild to moderate forms of anaemic conditions. Moreover, they are also at greater risk for adverse health conditions such as obesity, hypertension, and high blood glucose level.
\end{abstract}

Keywords: auto-rickshaw driver; obesity; hypertension; anaemia; education 


\section{INTRODUCTION}

The burden of health problems in developing countries continues to increase every year. Rapid urbanization and industrialization of metropolitan areas have contributed to serious environmental pollution and declining outdoor air quality in cities. Automobile exhausts are one of the major factors that continue to deteriorate the air quality. Petroleum and diesel fumes contain hazardous air pollutants which are harmful to our body. The major sources of such air pollutants are nitrogen dioxide, particulate matter, sulphur dioxide, ozone, and carbon monoxide. Exposure to these fumes has been shown to negatively affect the health of the population. Research shows that long term exposure to automobile exhausts contributes to heart diseases, asthma, chronic bronchitis, and other respiratory illnesses. Several studies have also reported that cardiovascular and respiratory system related mortality is most commonly associated with drivers who spend much time in traffic pollution $[1,2,3]$.

Auto-rickshaw is one of the primary modes of public transportation in India. It is very common in urban and semi-urban areas and even in cities. Auto-rickshaw drivers are directly and continuously exposed to the harmful working environment, and they are at greater risk of health problems, such as lungs impairment and heart diseases. Because of the nature of their occupation, they also have to tolerate other stressful working conditions, such as occupational stress, increase in workload, overtime working, tension, anxiety, noise, hostile work environment, and many others. It is evident from various studies that auto-rickshaw drivers suffer from different occupational diseases. An epidemiological study among the rickshaw drivers of Karachi, Pakistan, reported that respiratory infection, cardiac problems, headache, fatigue, stress, back pain and high blood pressure are the common health conditions of the drivers who are exposed for a long term to congested traffic air and noise pollution [4]. A study conducted among the auto-rickshaw drivers of Delhi reported high respiratory morbidity due to exposure to pollution [5]. High levels of psychological and physical stress have been reported particularly among the upper lower (29.8\%) and lower middle class (34.5\%) auto-rickshaw drivers of Bangalore [6]. In a recent study, effects of outdoor air pollution on pulmonary function causing lung disease have been reported among the auto-rickshaw drivers in the city of Bangalore [7].

Manipur, one of the north-eastern states of India, has a high literacy rate combined with high unemployment rates among educated people. Rise in unemployment, particularly among educated youths and adults, makes them choose different ways of earning their living. Driving an auto-rickshaw has 
become one of the most common and easiest ways of earning in the state, particularly in the plain districts of Manipur. It helps them to earn their daily needs as well as to support their family members. It could be the one of the reasons for the exponential growth of auto-rickshaws in the capital, Imphal, in recent years. Another reason may also be the increase in population, which accelerates the demand for a public transport system in the city and its surroundings. However, according to the knowledge of the authors, not a single study has been carried out among the auto-rickshaw drivers of Manipur, and no literature is available, particularly on their health conditions. It is essential to monitor the health conditions particularly of those auto-rickshaw drivers who are continuously exposed to the air and noise pollution for a long time. Therefore, the present study aims to determine the health conditions of the auto-rickshaw drivers working in Imphal, Manipur.

\section{MATERIALS AND METHODS}

The present study was carried out among the auto-rikshaw drivers who have worked in different locations of Imphal, Manipur, for more than one year. A total of 159 auto-rikshaw drivers, aged from 20-65 years, were randomly screened using the cross-sectional method. Data pertaining to personal information, socio-economic status, food habits, substance abuse, lifestyle, and medical history were obtained using a pre-tested structured interview schedule after getting their consent for participation in the study. The data were categorised into three subgroups with respect to the extent of engagement (years) in the occupation. Auto-rikshaw drivers who had been driving for up to 5 years were categorised into Group A. Those who had been driving for 5-10 years were categorised into Group B, and the participants who had been driving for more than 10 years were categorised into Group C.

\section{Health Parameters}

Systolic and diastolic blood pressure (SBP and DBP) were measured three times with an interval of 5 minutes after resting sitting for 5 minutes in all the participants using mercury sphygmomanometers and stethoscopes. Hypertension was categorised according to the Joint National Committee 7 (JNC-7) guidelines for the Management of Hypertension in Adults. Individuals with SBP $<120 \mathrm{mmHg}$ and DBP $<80 \mathrm{mmHg}$ were considered as normotensive and persons with SBP 120-139 $\mathrm{mmHg}$ and/or DBP $80-89 \mathrm{mmHg}$ as pre-hypertensive. Those having 
SBP $>140 \mathrm{mmHg}$ and/or DBP $>90 \mathrm{mmHg}$ or persons undergoing medication for hypertension were identified as hypertensive.

To understand the risk for developing obesity, the nutritional status with respect to body mass index (BMI) and waist-hip ratio (WHR) was examined following the Asia-Pacific BMI classification system. Individuals with $\mathrm{BMI}<18.5$ were categorised as underweight; with BMI ranges from 18.5-22.9 as normal; $23-24.9 \mathrm{BMI}$ as overweight and BMI $\geq 25$ as obese. Central obesity was evaluated in all the participants using the standard specific cut-off points of WHR. Individuals with WC $>94, \mathrm{HC}>102$ and WHR $\geq 0.90$ were categorised as high range, which means a risk for developing obesity.

Random blood glucose level (RBGL) was assessed using the Accu-Chek Active glucose meter. Random glucose levels were categorised according to the American Diabetes Association guidelines as hypo $(<79 \mathrm{mg} / \mathrm{dL})$, normal (79-139.99 mg/dL), pre-diabetes (140-199.99 mg/dL) and diabetes ( $\geq 200 \mathrm{mg} / \mathrm{dL})$.

Haemoglobin level was checked using Hemocheck based on the colour scale method. The results were categorised into different groups based on the National Health Portal, India, as normal ( $\geq 13 \mathrm{mg} / \mathrm{dl}$ ), mild anaemia $(11-12.9 \mathrm{mg} / \mathrm{dl})$, moderate anaemia $(8-10.9 \mathrm{mg} / \mathrm{dl})$ and severe anaemia $(<8 \mathrm{mg} / \mathrm{dl})$.

\section{Statistical Analysis}

Descriptive statistical analysis was performed using MS Excel and SPSS software (15.0 Version) to understand the effects of exposure to the harmful environment. Association of long term exposure to the harmful environment was also evaluated by Pearson's $\chi 2$-test followed by odds ratio (OR) at ninetyfive percent confidential interval (CI), using the freely available $2 \times 2$ contingency table (http://vassarstats.net/odds2x2.html). Statistical significance was considered at five percent level $(\mathrm{p}<0.05)$.

\section{RESULTS}

Of the 159 auto-rikshaw drivers, 80 (50.31\%) fell into Group A; 49 (30.82\%) were in Group B and 30 (18.87\%) in Group C. The mean age of the auto-rikshaw drivers in Groups $B$ and $C$ was significantly higher than the mean age of group A $(p<0.05)$. The majority of the auto-rikshaw drivers were married $(94.97 \%)$ except a few percent in Group A. Group A got married at a significantly earlier age $(26.43 \pm 5.30)$ than Group C $(28.77 \pm 5.17)(\mathrm{p}=0.04)$. Therefore, early 
age at marriage could be one of the possible factors for choosing to drive an auto-rickshaw as their primary occupation to support their family members (Table 1).

Table 1. Socio-economic and life style variables among different categories of auto-rikshaw drivers

\begin{tabular}{|c|c|c|c|c|c|c|}
\hline & & \multirow{2}{*}{$\begin{array}{c}\text { Group A } \\
(n, \%)\end{array}$} & \multirow{2}{*}{$\begin{array}{c}\text { Group B } \\
(n, \%)\end{array}$} & \multirow{2}{*}{$\begin{array}{c}\text { Group C } \\
(n, \%)\end{array}$} & \multicolumn{2}{|c|}{$\begin{array}{c}\text { Chi Square } \\
\text { (p-value) }\end{array}$} \\
\hline \multicolumn{2}{|c|}{ Characteristics } & & & & p1 & p2 \\
\hline Age (years) & Mean \pm SD & $36.02 \pm 9.73$ & $42.84 \pm 9.67$ & $47.53 \pm 9.57$ & $0.0002^{a^{*}}$ & $0.0001^{a^{*}}$ \\
\hline \multirow{2}{*}{ Marital status } & Unmarried & $8(10.0)$ & 0 & 0 & \multirow{2}{*}{$0.022^{*}$} & \multirow{2}{*}{0.072} \\
\hline & Married & $72(90.0)$ & 49 (100) & $30(100)$ & & \\
\hline $\begin{array}{l}\text { Age at } \\
\text { marriage }\end{array}$ & Mean $\pm S D$ & $26.43 \pm 5.30$ & $27.81 \pm 5.27$ & $28.77 \pm 5.17$ & $0.161^{a}$ & $0.04^{\mathrm{a}^{*}}$ \\
\hline \multirow{4}{*}{$\begin{array}{l}\text { Educational } \\
\text { status }\end{array}$} & Illiterate & $01(1.25)$ & $02(4.08)$ & $01(3.33)$ & \multirow{4}{*}{$0.004^{*}$} & \multirow{4}{*}{$0.003^{*}$} \\
\hline & Secondary & $03(3.75)$ & $11(22.45)$ & $08(26.67)$ & & \\
\hline & $\begin{array}{l}\text { Higher } \\
\text { Secondary }\end{array}$ & $64(80.0)$ & $23(46.94)$ & $18(60.00)$ & & \\
\hline & $\begin{array}{l}\text { Graduate \& } \\
\text { above }\end{array}$ & $12(15.0)$ & $13(26.53)$ & $03(10.00)$ & & \\
\hline \multirow{3}{*}{$\begin{array}{l}\text { Income } \\
\text { (per month) }\end{array}$} & $\begin{array}{l}\text { Upto } \\
\text { Rs.15,000/- }\end{array}$ & $34(42.5)$ & 24 (48.98) & $18(60.0)$ & \multirow{3}{*}{0.472} & \multirow{3}{*}{0.055} \\
\hline & $\begin{array}{l}\text { Rs. }(15,000- \\
20,000)\end{array}$ & $26(32.5)$ & $11(22.45)$ & $3(10.0)$ & & \\
\hline & $\begin{array}{l}\text { Above } \\
\text { Rs.20,000/- }\end{array}$ & $20(25.0)$ & $14(28.57)$ & $9(30.0)$ & & \\
\hline $\begin{array}{l}\text { Smoking } \\
\text { status }\end{array}$ & Yes & $41(51.25)$ & $20(40.82)$ & $16(53.33)$ & 0.249 & 0.846 \\
\hline $\begin{array}{l}\text { Tobacco } \\
\text { consumption }\end{array}$ & Yes & $43(53.75)$ & 24 (48.98) & $20(66.67)$ & 0.599 & 0.223 \\
\hline Pan & Yes & 47 (58.75) & $30(61.22)$ & $21(70.00)$ & 0.781 & 0.279 \\
\hline $\begin{array}{l}\text { Alcohol } \\
\text { consumption }\end{array}$ & Yes & $46(57.5)$ & 24 (48.98) & $20(66.67)$ & 0.346 & 0.382 \\
\hline
\end{tabular}

p-value: p1 - Group A vs Group B; p2 - Group A vs Group C; ${ }^{a}$ Unpaired $t$-test; *Statistically significant $(p<0.05)$. 
The number of dependent family member ranged from 1 to 11 , and the majority of the drivers (72.95\%) had 3-5 dependent family members. Approximately half of the auto-rikshaw drivers $(50.31 \%)$ had been driving for nearly 5 years, while $5.03 \%$ had been driving for 20 years and above. Most of the drivers $(81.13 \%)$ drive 7 days a week, and $50.94 \%$ of drivers ply on an average for more than 10 hours daily. Physical exercise is not performed by most of the auto-rikshaw drivers, and $28.30 \%$ of the drivers sleep less than 8 hours a day.

In general, the majority of the auto-rikshaw drivers are educated. However, low-grade educational status is commonly observed among Groups B and C. Most of the participants earn an income of up to Rs.15,000/- per month. Earning of income shows a borderline significant difference between Group A and Group C ( $\mathrm{p}=0.05)$. The most commonly abused substance is pan $(61.63 \%)$, followed by alcohol consumption (56.60\%), chewing tobacco (54.72\%), and smoking (48.43\%). However, no significant difference was observed among the different sub-groups of auto-rikshaw drivers (Table 1).

The occupation-related morbidity conditions generally encountered by auto-rickshaw drivers due to continuous exposure to polluted environment include vision effects, hearing problems, headache, pains in the leg, neck, back and arm. The most common type of occupation-related morbidity conditions faced by auto-rikshaw drivers are eyesight problems (blurring, tearing, irritation and burning), and body pain (neck, leg, arm, and back). Both problems were experienced by more than $50 \%$ of auto-rikshaw drivers, and the morbidity conditions were slightly more frequent in Group A. Body weight gain and loss were significantly higher among group C (43.33\% and $23.33 \%$ respectively) while compared with group A (36.25\% and $6.25 \%$ respectively) $(\mathrm{p}=0.013)$ (Table 2). It could be due to long term exposure of the auto-rikshaw drivers to the hostile environment as well as the physically inactive nature of their occupation.

The mean values of BMI, WHR, SBP, and DBP were above the normal cut-off values in all the sub-categories of auto-rikshaw drivers. However, the mean haemoglobin level $(11.8 \pm 1.03)$ was significantly lower than the normal cut-off point, suggesting a high prevalence of anaemia among the autorikshaw drivers. Auto-rikshaw drivers who had been driving for more than 10 years (Group C) showed a significant increase in the mean values of SBP (138.53 \pm 16.10$)$, DBP $(95.43 \pm 12.52)$, and RBGL (174.9 \pm 68.57$)$ as compared to Group A ( $\mathrm{p}<0.05)$. The results of the present study suggest that long-term service in the occupation as auto-rikshaw drivers is more prone to lead to adverse health outcomes (Table 3 ). 
Table 2. Types of morbidity conditions among different categories of auto-rickshaw drivers

\begin{tabular}{|c|c|c|c|c|c|c|}
\hline \multirow{2}{*}{\multicolumn{2}{|c|}{ Types of Morbidity Conditions }} & \multirow{2}{*}{$\begin{array}{c}\text { Group A } \\
(n, \%)\end{array}$} & \multirow{2}{*}{$\begin{array}{c}\text { Group B } \\
(\mathrm{n}, \%)\end{array}$} & \multirow{2}{*}{$\begin{array}{c}\text { Group C } \\
(n, \%)\end{array}$} & \multicolumn{2}{|c|}{$\begin{array}{l}\text { Chi Square } \\
\text { (p-value) }\end{array}$} \\
\hline & & & & & p1 & p2 \\
\hline \multirow{2}{*}{$\begin{array}{l}\text { Eye problem (blur, tears, } \\
\text { irritation, burning) }\end{array}$} & No & $37(46.25)$ & $23(46.94)$ & $18(60.0)$ & \multirow{2}{*}{0.939} & \multirow{2}{*}{0.199} \\
\hline & Yes & $43(53.75)$ & $26(53.06)$ & $12(40.0)$ & & \\
\hline \multirow{2}{*}{ Hearing impairment } & No & $74(92.5)$ & $46(93.88)$ & $29(96.67)$ & \multirow{2}{*}{0.766} & \multirow{2}{*}{0.425} \\
\hline & Yes & $6(7.5)$ & $3(6.12)$ & $1(3.33)$ & & \\
\hline \multirow{2}{*}{ Headache } & No & $66(82.5)$ & $44(89.79)$ & $27(90.0)$ & \multirow{2}{*}{0.256} & \multirow{2}{*}{0.332} \\
\hline & Yes & $14(17.5)$ & $5(10.20)$ & $3(10.0)$ & & \\
\hline \multirow{2}{*}{$\begin{array}{l}\text { Body pain (arm, back, neck } \\
\text { and Leg) }\end{array}$} & No & $36(45.0)$ & $23(46.94)$ & $18(60.0)$ & \multirow{2}{*}{0.830} & \multirow{2}{*}{0.161} \\
\hline & Yes & $44(55.0)$ & $26(53.06)$ & $12(40.0)$ & & \\
\hline \multirow{2}{*}{ Anxiety } & No & $57(71.25)$ & $29(59.18)$ & $22(73.33)$ & \multirow{2}{*}{0.158} & \multirow{2}{*}{0.829} \\
\hline & Yes & $23(28.75)$ & $20(40.82)$ & $8(26.67)$ & & \\
\hline \multirow{3}{*}{ Weight gain } & No & $46(57.5)$ & $26(53.06)$ & $10(33.33)$ & \multirow{3}{*}{0.494} & \multirow{3}{*}{$0.013^{\prime}$} \\
\hline & Yes & $29(36.25)$ & $17(34.69)$ & $13(43.33)$ & & \\
\hline & Loss & $5(6.25)$ & $6(12.24)$ & $7(23.33)$ & & \\
\hline \multirow{2}{*}{ Tired constantly } & No & $67(83.75)$ & $40(81.63)$ & $23(76.67)$ & \multirow{2}{*}{0.756} & \multirow{2}{*}{0.391} \\
\hline & Yes & $13(16.25)$ & $9(18.37)$ & $7(23.33)$ & & \\
\hline
\end{tabular}

p-value: p1 - Group A vs Group B; p2 - Group A vs Group C; *Statistically significant ( $<0.05)$.

Table 3. Comparison of mean values of anthropometric, physiological, and biochemical variables among different categories of auto-rickshaw drivers

\begin{tabular}{lccccc}
\multicolumn{1}{c}{$\begin{array}{c}\text { Parameters } \\
\text { (Cut-off point) }\end{array}$} & $\begin{array}{c}\text { Group A } \\
\text { (Mean } \pm \text { SD) }\end{array}$ & $\begin{array}{c}\text { Group B } \\
(\text { Mean } \pm \text { SD) }\end{array}$ & $\begin{array}{c}\text { Group C } \\
(\text { Mean } \pm \text { SD) }\end{array}$ & p1 & p2 \\
\hline BMI $(<23)$ & $25.37 \pm 3.26$ & $25.79 \pm 3.27$ & $26.11 \pm 3.24$ & 0.479 & 0.291 \\
\hline WC $(<90)$ & $87.79 \pm 9.65$ & $89.35 \pm 9.67$ & $89.67 \pm 9.68$ & 0.375 & 0.365 \\
\hline WHR $(\leq 0.9)$ & $0.95 \pm 0.07$ & $0.95 \pm 0.07$ & $0.96 \pm 0.07$ & 1.00 & 0.506 \\
\hline SBP $(<120)$ & $131.36 \pm 16.16$ & $134.82 \pm 16.05$ & $138.53 \pm 16.10$ & 0.239 & $0.041^{*}$ \\
\hline DBP $(<80)$ & $89.06 \pm 12.29$ & $89.71 \pm 12.29$ & $95.43 \pm 12.52$ & 0.771 & $0.018^{*}$ \\
\hline Hb Level $(\geq 13)$ & $12.26 \pm 1.03$ & $12.14 \pm 1.02$ & $11.8 \pm 1.03$ & 0.520 & $0.039^{*}$ \\
\hline Random Blood Glucose & $115.19 \pm 65.98$ & $125.71 \pm 65.39$ & $174.9 \pm 68.57$ & 0.379 & $0.0001^{*}$ \\
$(<140)$ & & & & &
\end{tabular}

p-value: p1 - Group A vs Group B; p2 - Group A vs Group C; *Statistically Significant $(p<0.05)$. 
Odds ratio (OR) was calculated to understand the association (if any) between auto-rikshaw drivers and variables considered in the present study. Both Groups B and C were found to have more than onefold increased risk of obesity, abdominal obesity (high WHR), hypertension, anaemia, and suspected diabetes while comparing with Group A. Auto-rikshaw drivers who had been driving for more than 10 years (Group C) showed more than fourfold significant increase risk for high blood glucose level compared with those who have been in the same occupation for up to 5 years $(\mathrm{OR}=4.18, \mathrm{p}=0.002)$ (Table 4$)$.

Table 4. Odds ratio between different categories of auto-rikshaw drivers and health parameters

\begin{tabular}{|c|c|c|c|c|c|c|}
\hline & & $\begin{array}{c}\text { Group A } \\
(n, \%)\end{array}$ & $\begin{array}{c}\text { Group B } \\
(n, \%)\end{array}$ & $\begin{array}{c}\text { Group C } \\
(n, \%)\end{array}$ & $\begin{array}{c}\text { OR' } 195 \% \mathrm{Cl} \\
\text { (p-value) }\end{array}$ & $\begin{array}{c}\text { OR }^{2} 95 \% \mathrm{Cl} \\
\text { (p-value) }\end{array}$ \\
\hline \multirow[b]{2}{*}{ BMI } & Normal & $17(21.25)$ & $11(22.45)$ & $06(20.0)$ & \multirow{2}{*}{$\begin{array}{c}0.93 \mathrm{Cl} 0.39- \\
2.20(0.86)\end{array}$} & \multirow{2}{*}{$\begin{array}{c}1.08 \mathrm{Cl} 0.38- \\
3.06(0.89)\end{array}$} \\
\hline & $\begin{array}{l}\text { Overweight } \\
\text { \& obese }\end{array}$ & $63(78.75)$ & $38(77.55)$ & $24(80.0)$ & & \\
\hline \multirow{2}{*}{ WC } & Normal & $58(72.5)$ & $31(63.26)$ & $21(70.0)$ & \multirow{2}{*}{$\begin{array}{c}1.53 \mathrm{Cl} 0.71- \\
3.27(0.27)\end{array}$} & \multirow{2}{*}{$\begin{array}{c}1.13 \mathrm{Cl} 0.45- \\
2.84(0.79)\end{array}$} \\
\hline & High & $22(27.5)$ & $18(36.73)$ & $09(30.0)$ & & \\
\hline \multirow{2}{*}{ WHR } & Normal & $23(28.75)$ & 09 (18.37) & $06(20.0)$ & \multirow{2}{*}{$\begin{array}{c}1.79 \mathrm{Cl} 0.75- \\
4.28(0.18)\end{array}$} & \multirow{2}{*}{$\begin{array}{r}1.61 \mathrm{Cl} 0.58 \\
4.46(0.35)\end{array}$} \\
\hline & High & $57(71.25)$ & $40(81.63)$ & $24(80.0)$ & & \\
\hline \multirow{2}{*}{$\begin{array}{l}\text { Blood } \\
\text { Pressure }\end{array}$} & Normal & $06(7.50)$ & $06(12.24)$ & $01(3.33)$ & \multirow{2}{*}{$\begin{array}{c}0.58 \text { Cl } 0.18- \\
1.91(0.368)\end{array}$} & \multirow{2}{*}{$\begin{array}{l}2.35 \mathrm{Cl} 0.27 \\
20.39(0.425)\end{array}$} \\
\hline & Hypertension & $74(92.5)$ & $43(87.75)$ & $29(96.67)$ & & \\
\hline \multirow{2}{*}{$\begin{array}{l}\mathrm{Hb} \\
\text { Level }\end{array}$} & Norm & $32(40$ & $19(38.77)$ & $07(23.33)$ & \multirow{2}{*}{$\begin{array}{c}1.05 \mathrm{Cl} 0.51- \\
2.18(0.89)\end{array}$} & \multirow{2}{*}{$\begin{array}{r}2.19 \mathrm{Cl} 0.84 \\
5.70(0.10)\end{array}$} \\
\hline & Anaemia & $48(60.00)$ & $30(61.22)$ & $23(76.67)$ & & \\
\hline \multirow[t]{2}{*}{ RBGL } & Normal & $69(86.25)$ & $42(85.71)$ & $18(60.0)$ & \multirow{2}{*}{$\begin{array}{c}1.04 \mathrm{Cl} 0.38- \\
2.91(0.92)\end{array}$} & \multirow{2}{*}{$\begin{array}{l}4.18 \mathrm{Cl} 1.59 \\
11.02(0.002)\end{array}$} \\
\hline & High & $11(13.75)$ & $07(14.28)$ & $12(40.0)$ & & \\
\hline
\end{tabular}

OR' - Group A vs Group B; OR² - Group A vs Group C; *Statistically Significant ( $p<0.05)$.

\section{DISCUSSION}

One's health condition is influenced by various factors, including the environmental condition and types of occupation. Occupational health problems have become one of the major health concerns for epidemiologists. Among different types of occupation, auto-rickshaw driving has been chosen by a large number of unemployed youths as it is a widely demanded job in most places in India and its neighbouring countries. This occupation involves health risks which are generally ignored by auto-rikshaw drivers as well as the government health service providers as they are unaware of them. The drivers have been 
continuously exposed to drastic working environment conditions which significantly cause various complex diseases and many other forms of morbidities.

The illiteracy rate in the present study was very low (2.51\%) in contrast with other studies where it reached up to $31 \%[8,9]$. The findings of the present study indicate a high prevalence of unemployed educated youths in the state. Auto-rikshaw drivers plying in Imphal generally earn a good income. However, their income is greatly affected by frequent bandh and general strike calls by different civil organizations on different issues. On the other hand, their income is also influenced by the exponential growth in the number of auto-rickshaw drivers. Earning of fluctuating and not permanent income by the auto-rikshaw drivers and their struggle to meet the daily requirements as well as pay for children's education is in accordance with other studies [10,11].

Substance abuse such as chewing of tobacco, consumption of pan, smoking, and alcohol consumption is found to be very common among the auto-rikshaw drivers. The high prevalence of substance abuse in the present study $(81.76 \%)$ is in accordance with other studies conducted among auto-rikshaw drivers from different parts of the country. The majority of the auto-rikshaw drivers from Jaipur, Rajasthan (87.2\%), abused tobacco products in one or another form [12]. The finding of the present study is further supported by other similar studies reporting a high prevalence of substance abuse by auto-rikshaw drivers $[13,14,15]$. The present study showed a comparatively higher prevalence of alcohol consumption (56.60\%) than the other studies reported among the auto-rikshaw drivers plying in various locations [16, 17]. Further, autorikshaw drivers of Vashi, Navi Mumbai, consumed alcohol at a comparatively low rate [14].

The most common health problems experienced by auto-rikshaw drivers as reported by different studies include back pain, eyesight problems, and respiratory problems $[11,15]$. The majority of the auto-rikshaw drivers in the present study had ill health experiences of body pain in concurrence with other studies. Moreover, studies reported that musculoskeletal pain (back pain, knee pain) was the major morbidity condition complaint by the auto-rikshaw drivers $[15,18]$. It is evident that auto-rickshaw drivers had a poor health condition which is associated with their occupation as it involves long-term sitting while driving, vibration of the whole body, exposure to both air and noise pollution over a long time.

The prevalence of mild anaemia (59.12\%) in the present study exceeds the rate of 25.45\% reported among the auto-rikshaw drivers plying in Agra city [19]. However, no severe cases of anaemia were observed in the present study, 
which is in contrast with Singh et al. who reported $1.14 \%$ of severe anaemic cases among the drivers plying in Agra. The rate of undiagnosed suspected diabetic individuals found in the present study is consistent with other studies reporting a high incidence of suspected diabetes among the auto-rikshaw drivers [15].

A recent study reported high prevalence of overweight, obesity class I, and high WHR among the auto-rikshaw drivers of Hyderabad [9]. The findings of the present study reaffirm that driving, which involves continuous prolonged sitting, is associated with obesity [15]. However, studies on the same occupation group have also reported high prevalence of underweight among the autorikshaw drivers suggesting a double impact on body weight due to their nature of work $[18,19]$. Moreover, it could also be due to inequalities of economic status among the auto-rikshaw drivers.

The high incidence of hypertensive cases in the present study (64.15\%) is in accordance with previous studies suggesting that auto-rickshaw drivers are more prone to have hypertension. Moreover, the risk of hypertension increases among the drivers who have been driving over a long period of time. Most of the pre-hypertensive and hypertensive individuals observed in the present study were undiagnosed cases. They were not aware of their hypertensive status. High incidence of hypertensive cases was also reported among the autorikshaw drivers plying in different cities $[9,19]$. However, some of the studies report a relatively low rate of hypertensive cases among the auto-rikshaw drivers $[13,15,16]$.

\section{Limitations and implications}

The present study has not assessed some of the important determinants of health, such as lipid profile, hearing ability, air pollutants and their level in the study area, and physical efficiency due to time and financial constraint. The data were collected from different auto-rikshaw drivers parking during the peak hours of their service, and the assessment of variables is also a timeconsuming process. Hence, a limited amount of data could be collected; therefore, the small sample size is one of the major limitations.

Such occupational health studies may be carried out comparing with age-sex matched unexposed healthy controls in a large population to explore the occupationally related risk factors. The findings of the present study suggest that auto-rikshaw drivers have poor health conditions. The effect is more pronounced among the auto-rikshaw drivers who have been engaged in the occupation for a long time. Therefore, further studies can also be carried out 
among the populations who are working in different sectors (public transport services, shopkeepers, traffic police) and also people living in and around the city who are also equally exposed to the same environment as the autorikshaw drivers.

\section{CONCLUSION}

The present study concludes that auto-rickshaw drivers who have worked for more than 10 years are more prone to have adverse health outcomes than drivers who have been driving for 1-5 years. Moreover, being engaged the same occupation continuously for a long period of time is also associated with mild to moderate forms of anaemic conditions, obesity, high WHR, hypertension, and high RBGL. Regular health check-up, diagnosis, and occupational health awareness programmes should be performed as an interventive measure to reduce the morbidity and immature mortality rate among the auto-rikshaw drivers. This would help to improve both their health and socio-economic status. Individuals possessing more risk factors should be advised to take precautions as well as to modify their lifestyle, and also to keep physically active to protect themselves from adverse health outcomes. Such health issues need to be addressed to prevent severe health outcomes as well as to improve and protect their social status in society.

\section{ACKNOWLEDGEMENT}

The authors would like to acknowledge the Department of Science and Technology of Manipur for giving financial assistance to carry out the research. The authors are also thankful to all the individuals who were involved in the present study for their voluntarily participation.

\section{CONFLICT OF INTEREST}

Authors have no conflicts of interest 


\section{REFERENCES}

1. Dockery D.W., Stone P.H. (2007). Cardiovascular risks from fine particulate air pollution. N Engl J Med, 356(5), 511-513. https://doi.org/10.1056/NEJMe068274

2. Pope C.A, Dockery D.W. (2006). Health effects of fine particulate air pollution: lines that connect. J Air Waste Manag Assoc, 56(6), 709-742. https://doi.org/10.1080/10473289.2006.10464485

3. Khan M.R. (2006). Banning two-stroke Auto-rickshaws in Lahore: Policy Implication. The Pak Dev Rev, 45, 1169-1185. https://doi.org/10.30541/v45i4IIpp.1169-1185

4. Hany O., Memon S., Neelam A., Alamgir A., Abid K. (2015). Epidemiological Study of Rickshaw Drivers Health Status and Accident Encounters in Towns of Karachi. Bull Env Pharmacol Life Sci, 4(12), 55-59.

5. Rajkumar. (1999). Effect of air pollution on respiratory system of auto rickshaw drivers in Delhi. Indian J Occup Environ Med, 3(4), 171-3.

6. Sinha A.K., Shashikala M. (2015). Assessment of stress among auto-rickshaw drivers in Bangalore city - a cross sectional study. Int J Pub Men Health Neurosciences, 2(1), 45-47.

7. Babu V.K., Damodar K.S. (2017). Effect of outdoor air pollution on pulmonary function of non-smoking auto-rickshaw drivers in Bangalore. Int J Clin Exp Physiol, 4, 30-3. https://doi.org/10.4103/ijcep.ijcep_53_16

8. Melwani V., Priya A., Toppo M., Sethia S., Khan A., Melwani S. (2018). Study to assess the socio-demographic profile, health status and working conditions of auto-rickshaw drivers in Bhopal. Int J Com Med Pub Health, 5, 1323-6. https://doi.org/10.18203/2394-6040.ijcmph20180971

9. Asma V.T., Jyothsna C., Manju S., Sowmya C., Devi C.G., Kumar D.V., Ravali D., Yeshaswini D., Mohan D.R. (2019). A cross sectional study on health status and prevalence of risk factors of non-communicable diseases among auto rickshaw drivers of Hyderabad, Telangana. Int J Com Med Pub Health, 6, 1279-84. https://doi.org/10.18203/2394-6040.ijcmph20190626

10. Kollambalath S.B. (2016). Health Risk of Auto Rickshaw Drivers around Silencer of Heavy Vehicles. IOSR J Environ Sci Toxicol Food Technol, 10(1), 9-14. https:// www.iosrjournals.org/iosr-jestft/papers/vol10-issue1/Version-1/C010110914.pdf

11. Elango L., Thairiyam D.M., Sharma P.K. (2018). A study on socio-economic and health status of auto drivers of Tiruppatur, Vellore District. Int J Curr Res Life Sci, 7(2), 1148-51.

12. Sudhir R., Poonia N., Singh N.K. (2013). A cross sectional study on tobacco consumption pattern among auto rickshaw drivers in Jaipur City, Rajasthan. IOSR J Human Soc Sci, 14(3), 88-91. https://doi.org/10.9790/1959-1438891 
13. Chaudhary S.S., Nagarjole M.M., Kubde S.S., Gupta S.C., Misra S.K. (2010). Prevalence of Cardiovascular Diseases risk factors among auto-rickshaw drivers. Indian J Com Health, 22(2), 32-4.

14. Rahaman M., Nurullah Awal A.S.M., Fukui T., Sakamoto J. (2007). Prevalence of cigarette and bidi smoking among rickshaw pullers in Dhaka city. Prev Med, 44(3), 218-22. https://doi.org/10.1016/j.ypmed.2006.11.001

15. Mahadik V.J., Waingankar P., Anjenaya S., Sanjeev S., Mali K. (2017). Crosssectional study of health status of auto-rickshaw drivers in Vashi, Navi Mumbai, India. MGM J Med Sci, 4(4), 164-170.

https://doi.org/10.5005/jp-journals-10036-1164

16. Girish H.O., Senan P., Koppad R., Venugopalan P.P. (2016). Risk factors of cardiovascular diseases among auto-rickshaw drivers of Kannur, North Kerala: a cross-sectional study. Int J Com Med Pub Health, 3(12), 3395-98. https://doi.org/10.18203/2394-6040.ijcmph20164262

17. Thankappan K.R., Shah B., Mathur P., Sarma P.S., Srinivas G., Mini G.K., Daivadanam M., Soman B., Vasan R.S. (2010). Risk factor profile for chronic non-communicable diseases: results of a community-based study in Kerala, India. Indian J Med Res, 131, 53-63.

18. Shaik R., Gotru C.K., Swamy C.G., Sandeep R. (2014). The prevalence of musculoskeletal disorders and their association with risk factors in auto-rickshaw drivers - a survey in Guntur city. Int. J Physiother, 1(1), 2-9.

19. Singh S.P., Misra S.K., Chaudhary S.S., Katyal R., Singh A., Joshi H.S. (2015). Health status of auto-rickshaw drivers plying in Agra city. Med Pulse-Int Med J, 2(4), 221-28.

\section{Address for Correspondence}

Huidrom Suraj Singh

Department of Anthropology

Manipur University

Canchipur, Imphal, Manipur - 795003, India

E-mail: huidromsurajsingh@gmail.com 